\title{
SPATIAL PATTERNS OF TREE SPECIES NUMBER IN RELATIONSHIP WITH THE LOCAL ENVIRONMENTAL VARIATIONS IN KARST ECOSYSTEM
}

\author{
TOURE, D. ${ }^{1 *}-$ GE, J. $^{1}-$ ZHOU, J. ${ }^{2}$ \\ ${ }^{1}$ Institute of Ecology and Environmental Sciences, School of Environmental Studies, China \\ University of Geosciences (Wuhan) \\ Hubei, 388 Lumo Lu, 430074, P.R China \\ (phone: +86-1597-299-3853) \\ ${ }^{2}$ Faculty of Environmental Geology, School of Environmental Studies, China University of \\ Geosciences, Wuhan, Hubei, P.R. China \\ *Corresponding author \\ e-mail: touredado@yahoo.fr \\ (Received 14 $4^{\text {th }}$ Jan 2015; accepted 21 $1^{\text {st }}$ March 2015)
}

\begin{abstract}
Karsts are recognized as fragile environments where, forest degradation is faster and the composition and growth rate of vegetation is considered as a product of the interactions between karst ecological factors. A representative sample of vegetation plots from a systematic sampling was analyzed in Longhushan, southwest China. The sampling combined measurements of species number with extensive information on geological, environmental, and soil factors to establish species response to the single or combined influence of these factors. Both General and Generalized Linear Models predicted richness as a function of the combination of variables from the three groups. Richness increased with elevation, slope, moisture, and in dolomite dominated areas, but decreased with organic matter. Patterns of richness were dependent on complex relationships between soil, geological, and environmental factors, within this complexity it appeared that rock type played an important role. Evidence of significant variations was provided after combining variables from the three groups, suggesting their interactions influence on plants. Our findings have implications for the understanding of these interactions and suggest that plant species can be affected by it, and also carbonate rock type may be an important parameter to consider while examining relationships between plant and environmental factors in karst areas.
\end{abstract}

Keywords: trends in plant species richness, environmental habitat factors, interactions, karst forest

\section{Introduction}

Plant communities and biodiversity are believed to have a high degree of spatial variability that is controlled by both abiotic and biotic factors. Many types of environmental changes may influence the processes that can both augment or erode diversity (Sagar et al., 2003). The understanding of patterns and processes of biological diversity in space is a fundamental problem in ecology and conservation (Rosenzweig, 1995; Moritz, 2002), given the increasing rates of species extinction and human alteration of natural habitats.

Richness, the number of species per unit area, is a simple and easily interpretable indicator of biological diversity (Peet, 1974). Plant richness is said to be likely governed by two or more environmental factors (Margules et al., 1987; Pausas, 1994; Austin et al., 1996) and variations in richness are often linked to various environmental gradients (Wang et al., 2002; Sharma et al., 2009). For instance, elevation gradients are one of the most commonly discussed determinative factors in shaping the spatial patterns of 
species richness (Lomolino, 2001; Chawla et al., 2008; Acharya et al., 2011). Studies on the variations in species richness along elevation gradients have resulted in at least five patterns and all trends have been discussed in relation to different environmental variables (Körner, 2002; Grytnes, 2003b; Rahbek, 2005). Topography is correlated with other important environmental variables including the physical and chemical properties of the soils. Topography has also an important role in controlling the distribution of light, heat, moisture, and the strength and frequency of disturbance (McDonald et al., 1996; Shen et al., 2000). However, most researches have mainly focused on the relationships between soil and plants or plants and topography (Wu et al., 2001; Gong et al., 2007; Yue et al., 2008), while further studies of their interrelationships is required (Liu et al., 2003; Ye et al., 2004).

The geology is also an important factor to consider when analyzing the spatial patterns of plant species. The influence of geology can be split into the direct influence of rock type itself (chemistry and physical structure), and the indirect role that it plays in soil formation as well as the development of structures that influence the distribution of plants at a range of scales (Cottle, 2004). Studies have shown associations between geological substrates and tree species distribution and community composition (Reiners, 2002; Tuomisto et al., 2003; Phillips et al., 2003; terSteege et al., 2006; Fayolle et al., 2012). Yet, there are limited examples showing the significance of the direct influence of rock type (its chemistry) on plant distribution (Cottle, 2004).

Properties of bedrock, soil, and topography are thus interrelated and associated with plant species, but the problem is to define what this association is and at what level. Examining simultaneously these factors could improve our understanding of the spatial patterns of plant species in a particular geological environment like karst mountains. Karst ecosystem, described as the ecosystem that is restrained by karst environment (Yuan, 2001), especially by karst geological setting (Cao et al., 2003), is recognized as a highly complex interactive system which incorporates component landforms, life, energy flows, water, gases, soils and bedrock. Perturbation of any one of these elements is likely to impact upon the others (Yuan, 1988; Eberhard, 1994). Recognition and understanding of the importance and vulnerability of this dynamic interaction must underpin the effective management and conservation of karst forest resources.

This research examines patterns in tree species richness and their ecological correlates in the karst forest of Longhushan Nature Reserve (LNR), southwest China (SW China). Located at the northern edge of tropical Asia, the karst landscape of SW China is one of the most typical landscapes developed on limestone in the world (Yuan, 1993; Liu, 2009). These mountains have unique types of vegetation (Zhang et. al., 2010) and evolved into a cluster of distinctive mini-hotspots. However, plant diversity is threatened by rapidly changing land use patterns in tropical Asia (Sodhi et al., 2010), where forests are becoming increasingly disturbed and fragmented (Sodhi et al., 2004; Laurance, 2007), so it is said that more effort should be made to document biodiversity in the region (Webb et al., 2010).

Due to the rapid increase of population and related excessive exploitation of the region's natural resources (habitat destruction, farming, logging, infrastructures, fuel wood, tourism, deforestation), the karst lands of SW China are faced with serious degradation sequences. The anthropogenic influence combined with the ecological fragility of the karst system often result not only in the loss of biological diversity, but also in forest degradation to shrubs, grasses, or even to rock desertification in some areas, making ecological restoration and reconstruction imperative (Wu et al., 2008; 
Song et al., 2008). LNR has the advantage of relatively well established vegetation even retaining the arbor layer, but also under significant anthropogenic influences which may exceed its environmental carrying capacity. The area is hence an ideal research habitat to study plant species, the range of environmental conditions in which they develop, and species patterns in such ecosystem.

The main purpose is to explore patterns in tree species richness and their relationships with the interactions among environmental habitat factors. The study intends to examine: 1) dominant species in plant communities; 2) rock type, soil characteristics, environmental factors, and their single effects on richness; 3) species richness response to the joint effects of rock type, soil and environmental factors; and 4) the dominant species distribution along significant environmental variables. These informations could be useful in the development of management, conservation, and restoration strategies of forest ecology and biodiversity in karst regions.

\section{Materials and methods}

\section{Site location and description}

The study was carried out in LNR located in the subtropical area of southern China at the northern edge of tropical Asia, Nanning city, Guangxi Zhuang Autonomous Region (Figure 1). LNR covers an area of 2255.7 hectares and is bounded between latitudes $22^{\circ} 56^{\prime}$ to $23^{\circ} 00^{\prime} \mathrm{N}$ and longitudes $107^{\circ} 27^{\prime}$ to $107^{\circ} 41^{\prime} \mathrm{E}$. The area has a monsoonal climate characteristic of the subtropical zone and is influenced by the regulation of a maritime climate. The annual average temperature is $21.8 \mathrm{C}^{\mathrm{o}}$, with the annual average precipitation of $1500 \mathrm{~mm}$ which is mostly centralized in summer. The reserve belongs to Guangxi which is recognized to have one of the key forest areas in southern China with high plant biodiversity. However, aside from being divided by a highway, the status of the area is that of a nature reserve and tourist attraction. Longhushan is also a primate reserve with an increasing impact from both primate population density and anthropogenic impacts through agriculture, facilities and infrastructure developed for tourism.

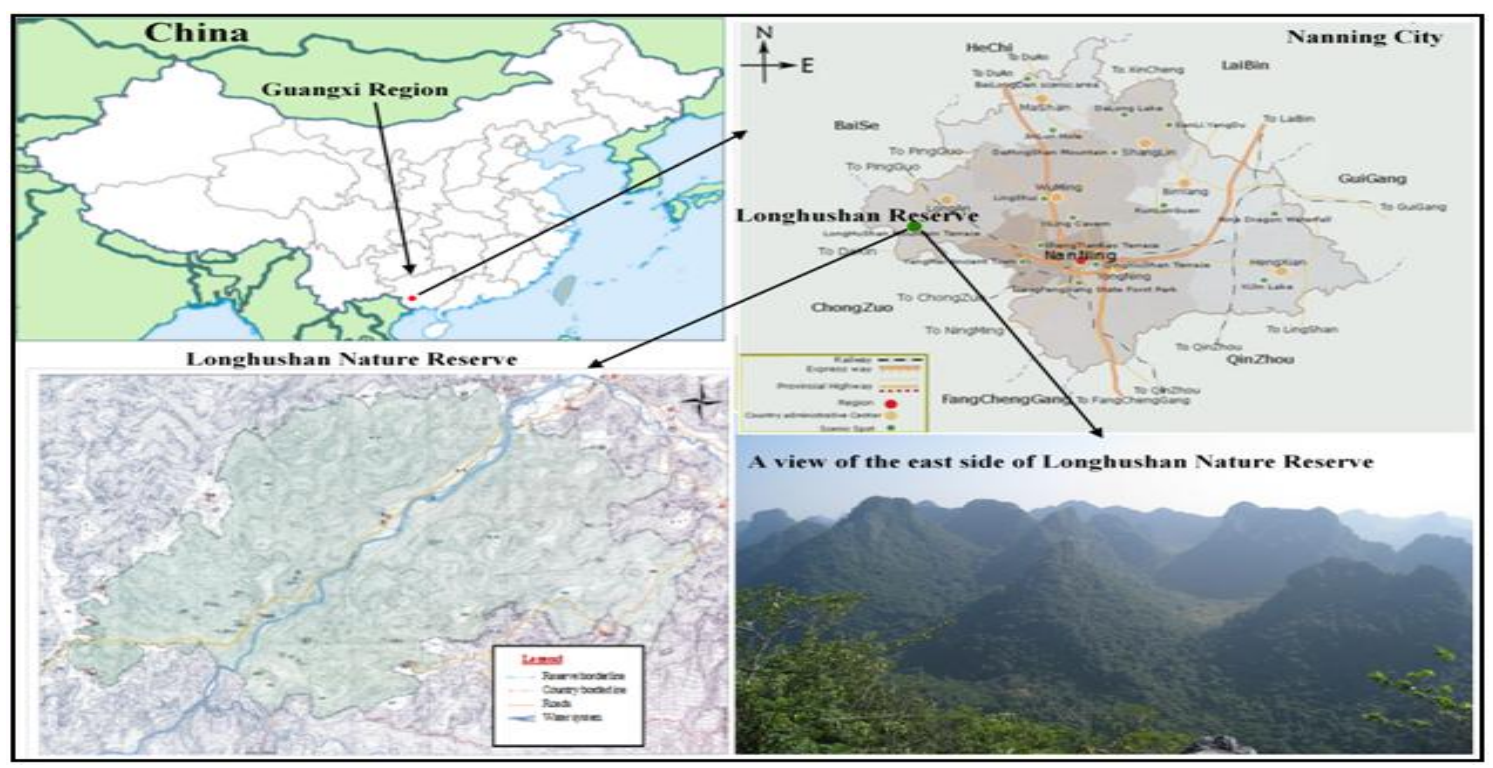

Figure 1. The location and presentation of LNR 


\section{Sampling design and analysis}

A representative sample of vegetation plots was analyzed from a systematic sampling implemented in the reserve, using 30 meters square quadrats randomly located along four south-north transects lines. The sampling combined measurements of plant species number per quadrat, with extensive information on rock type (RT), soil and other environmental variables, allowing for the direct consideration of the interactions between different environmental habitat factors. Rock and soil samples were collected from 17 quadrats, in addition to several environmental variables including elevation $(\mathrm{E})$, slope degree (Sd), canopy cover (CC), soil depth (SDp), ground temperature (GT), and ground cover (GC). Rock samples were collected from the outcrops on the surface of each quadrat, while soil samples were collected from the topsoil layers after the removal of leaf litter.

The basement material of karst is carbonate rock compose of limestone (mainly composed of calcite - $\mathrm{CaCO} 3$ ), and dolostone (composed of dolomite - CaMg (CO3)2). Rock samples were analyzed by a staining method for the percentage content of calcite and dolomite, using alizarin-red test (Friedman, 1959; Warne, 1962). Soil samples were examined for some major characteristics that have influence on other properties and nutrients availability, including texture (ST), moisture $(\mathrm{M}), \mathrm{pH}$, and organic matter (OM) content. Soil M was analyzed using the standard gravimetric method (oven-dry method), while $\mathrm{pH}$ was obtained using the soil-water suspension method. The classic rapid dichromate oxidation technique was used to determine soil organic carbon (Nielson and Sommers, 1982). Soil type was examined using the USDA method to determine soil textural classes based on percentage content of sand, silt, and clay.

\section{Statistical analysis}

Statistical analysis was conducted at $95 \%$ confidence interval $(\mathrm{p}<0.05 \mathrm{CI})$ using SPSS 19 software. Data were divided into four groups including one group of response variable (species richness or plant index), and three groups of predictors including soil characteristics (SDp, ST, M, pH, OM), geological factor (RT), and environmental factors (E, Sd, CC, GC, GT). Pearson's simple correlation tested the bivariate correlations between each predictor and richness as well as the correlations among the predictors. Analysis of variance (ANOVA) was applied to examine the effects of RT or ST (categorical variables) on plants by comparing the average species richness between different RT and ST levels. ANCOVA examined the influence of ST while controlling the effects of covariates from soil or environmental factors. Furthermore, predictors from all three groups were tested separately and then in combinations in four multiple linear regressions (MLR) models to find the best fit for richness. Models 1, 2, and 3 were designed to test the single effect of each group, while model 4 was fitted with combinations of variables selected from all three groups to predict richness. The equation to calculate the predicted value of richness for the significant model was established following the general form of the MLR function below.

$$
Y=A+B 1 X 1+B 2 X 2+\cdots B k X k
$$

Where $\mathrm{Y}$ is the response value of richness, $\mathrm{A}$ is the $\mathrm{y}$-intercept, $\mathrm{B}_{1}$ to $\mathrm{B}_{\mathrm{k}}$ represent the regression coefficients, $\mathrm{X}_{1}$ to $\mathrm{X}_{\mathrm{k}}$ are the different predictor variables. 
Moreover, as the effects of environmental variables on plant species may not be linear in nature, the generalized linear model (GzLM) expands the General Linear Model (GLM) so that richness is linearly related to the predictors via a specified link function, and also allows richness to have a non-normal distribution. Species richness being a count variable, Poisson model was selected as a reasonable candidate response distribution with the natural log as the link function. Predictors from all three groups of factors were tested separately and then collectively in several combinations (within and between groups) including and excluding different variables. Based on their goodness of fit (GOF) test statistics, four models were designed to show the effects of the interactions between variables from the three groups. As for the MLR analysis, models 1,2 , and 3 were designed to test richness as a function of the single groups of soil, geological, or environmental factors, while model 4 was fitted with combinations of variables from the three groups to predict richness. The predicted value of richness for the significant model was calculated following the general form of the Poisson regression $(\mathrm{PR})$ function, where the natural log of richness is predicted with a linear combination of the predictor variables.

$$
\begin{aligned}
& \log (\text { richness })=\text { Intercept }+B 1 X 1+B 2 X 2+\cdots B n X n \\
& \text { Richness }=(e)^{\text {Intercept }} \times(e)^{B 1 X 1} \times(e)^{B 2 X 2} \times \cdots(e)^{B n X n}
\end{aligned}
$$

Where $B_{1}, B_{2} \ldots B_{n}$ represent the regression coefficients and $X_{1}, X_{2} \ldots X_{n}$ the different environmental variables used as predictors in the models.

\section{Results}

\section{Characteristics of plant communities, soil and geological factors of the study area}

Table 1 presents the basic descriptive statistics of all variables examined. Dolomite dominated in 11 samples varying from 70 to $98 \%$, representing about $65 \%$ of the studied plots, from which more than $90 \%$ has dolomite content $\geq 90 \%$. Seventy five percent $(75 \%)$ of the studied area was dominated by fine and medium textured soil, while $25 \%$ was found with coarse and moderately coarse soils. Soil $\mathrm{pH}$ was moderately acidic in two plots (5.25 and 5.71) representing $11.76 \%$, while over $88 \%$ of the surveyed area was found with $\mathrm{pH}$ ranging between near neutral to moderately alkaline (6.66-7.91). This agrees with the results of previous studies (Liu, et. al., 2006; $\mathrm{Hu}$, et. al., 2009) in another southwest China karst area (Guizhou province). OM content interpreted according to Hartz, (2007) showed that nearly $53 \%$ of the study site was found with high OM content $(>5 \%)$ and $47 \%$ with low OM content $(<5 \%)$. Considering the moisture interpretation chart of Harris and Coppock, (1991), about $88.23 \%$ of the sampled plots has insufficient available moisture (50\% or less), whereas only $11.76 \%$ has sufficient available moisture (50 to $75 \%$ ). Plant communities were generally evergreen with delimitation between arbor layers, shrubs and grasses. A total of 59 species were recorded across the 17 quadrats from which Sterculia nobilis, Ficus sp., Albizia chinensis, Liquidambar formosana, Teonongia tonkinensis, and Bischofia javanica were the most dominant 
based on their importance value indices (Figure 2). Among them Sterculia nobilis was by far the most abundant representing about $14 \%$ of the total importance value.

Table 1. Descriptive statistics of all variables of interest from the four groups of factors $(N=17)$

\begin{tabular}{|c|c|c|c|c|c|c|}
\hline Groups of Factors & Factors & Min & Max & Mean & $\begin{array}{c}\text { Std. } \\
\text { Deviation }\end{array}$ & $\begin{array}{c}\text { Type of } \\
\text { Variables }\end{array}$ \\
\hline Plant index & Species richness & 3 & 12 & 7.18 & 3.11 & Response \\
\hline \multirow{4}{*}{ Soil characteristics } & Organic matter content $(\%)$ & 2.35 & 12.51 & 7.11 & 3.32 & \\
\cline { 2 - 6 } & Soil depth $(\mathrm{cm})$ & 3 & 100 & 34.29 & 36.71 \\
\cline { 2 - 6 } & $\mathrm{pH}$ & 5.25 & 7.91 & 7.30 & 0.79 \\
\cline { 2 - 6 } & Moisture $(\%)$ & 14.14 & 57.49 & 38.13 & 11.69 \\
\cline { 2 - 6 } & Soil texture & - & - & - & - \\
\hline Geological factor & Rock type & - & - & - & - \\
\hline \multirow{5}{*}{ Environmental factors } & Ground temperature $\left({ }^{\circ} \mathrm{C}\right)$ & 24.00 & 29.00 & 26.99 & 1.42 \\
\cline { 2 - 6 } & Ground cover $(\%)$ & 20 & 95 & 63.53 & 20.82 \\
\cline { 2 - 6 } & Canopy cover $(\%)$ & 40 & 90 & 65.00 & 16.45 \\
\cline { 2 - 6 } & Slope degree $\left({ }^{\circ}\right)$ & 5 & 60 & 23.71 & 16.72 \\
\cline { 2 - 6 } & Elevation $(\mathrm{m})$ & 109 & 243 & 150.82 & 35.16 & \\
\hline
\end{tabular}

Rock type was coded as $1=$ dolomite, $2=$ calcite; Soil texture was coded as $1=$ coarse textured soil, $2=$ moderately coarse, $3=$ medium, 4 = fine

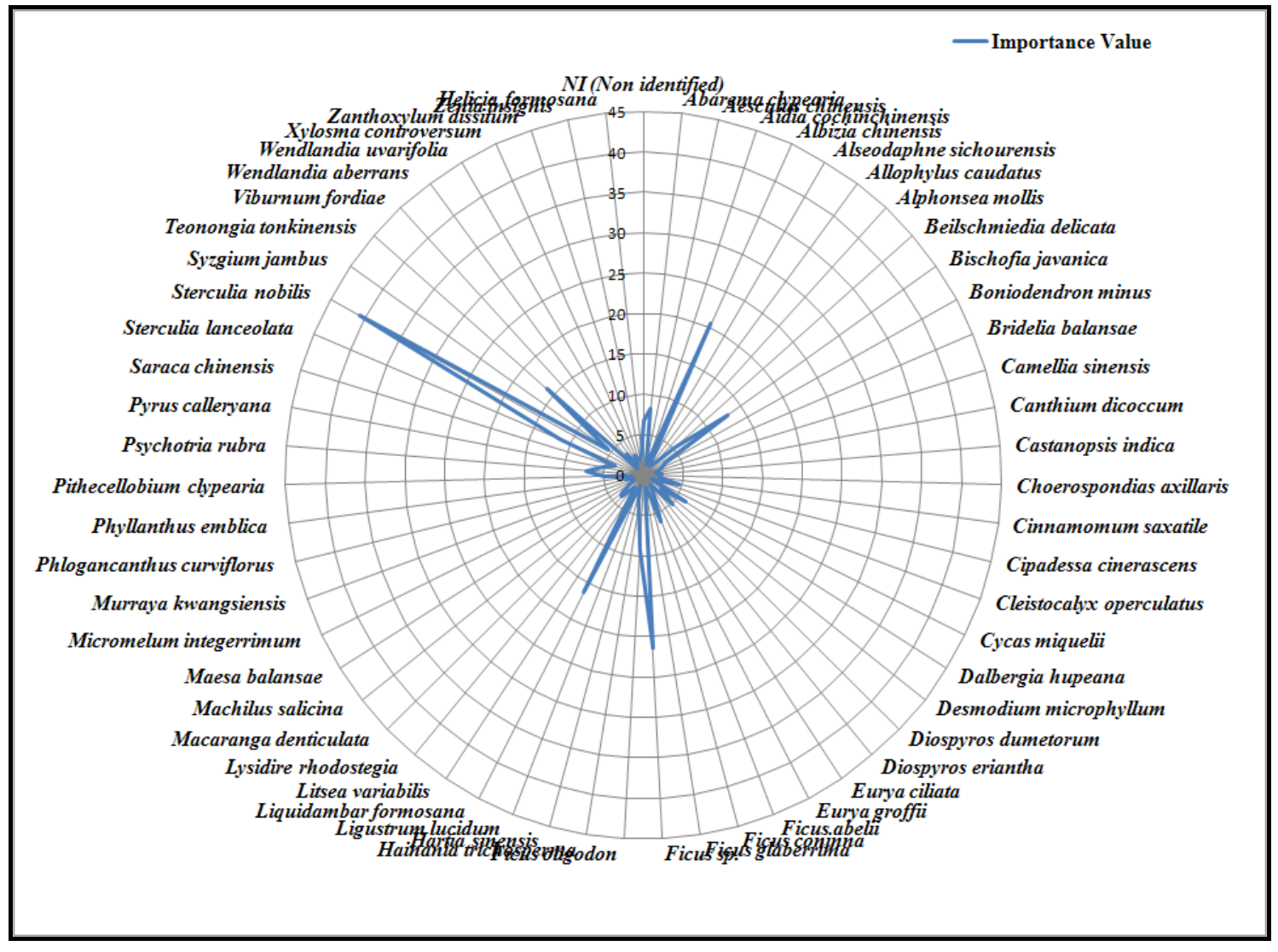

Figure 2. Importance values of 59 plant species recorded in LNR 


\section{Correlation, ANOVA and ANCOVA results}

Correlation analysis indicated no significant association between richness and any predictor except $\mathrm{Sd}(\mathrm{r}=0.542, \mathrm{p}<0.05)$, while few inter-correlations were found among some of the predictors with the highest between $\mathrm{M}$ and $\mathrm{OM}(\mathrm{r}=0.760, \mathrm{p}<0.01), \mathrm{SDp}$ and $\mathrm{pH}(\mathrm{r}=-0.661, \mathrm{p}<0.01)$. However, no correlation coefficient was equal or greater than 0.8 to fear for serious multicollinearity problem. ANOVA also found no significant changes in richness related to ST or RT, as the null-hypotheses were not rejected. With ANCOVA a fairly significant association was found when the joint effects of ST and RT were examined after controlling the effects of $M$ and GC. ST was found significantly related to richness $(\mathrm{F}=4.228, \mathrm{p}=0.040)$ accounting for $58 \%$ of its variance (Partial $\mathrm{Eta}^{2}=0.585$ ), with near $67 \%$ chance of finding a significant difference in our case (observed power $=0.667$ ). The highest impact was from medium textured soils which also registered the highest mean species richness, followed by moderately coarse, coarse, and fine soils.

\section{MLR models for richness response to the single or combined effects of geological, soil, and environmental factors}

Although model 2 was found marginally significant $(\mathrm{F}=2.860, \mathrm{p}=0.068)$, MLR analyses (Table 2) showed that the models $(1,2,3)$ designed with single groups of factors still failed to explain significant variations in richness, since in all three cases none of the null-hypotheses (F-ratio) was rejected ( $p>0.05)$. In contrast, model 4 fitted with combinations of variables from the three groups produced a correlation coefficient $(\mathrm{R}=0.956)$ which suggests at first, the existence of strong association between the five predictors and richness. Furthermore, unlike the previous models, model 4 explained significant variation in richness $(\mathrm{F}=23.318, \mathrm{p}<0.001)$, accounting for $87.5 \%$ of its variance (adj. $\left.R^{2}=0.875\right)$. Compared to models 1,2 , and 3 , the amount of variation accounted for in the response greatly increased by over $76 \%$, $100 \%$ and $50 \%$, respectively. Moreover, except OM found with a marginal effect $(\mathrm{t}=-2.100, \mathrm{p}=0.060)$, each predictor significantly explained richness $(\mathrm{p}<0.05)$ which increased with $\mathrm{E}, \mathrm{Sd}, \mathrm{M}$, and in dolomite dominated areas. The t-tests show that RT $(\mathrm{t}=-7.083, \mathrm{p}<0.001)$ and $\mathrm{Sd}(\mathrm{t}=7.105, \mathrm{p}<0.001)$ were the greatest contributors followed by $\mathrm{M}$ and $\mathrm{E}$, while $\mathrm{OM}$ was found with no significant effect. Figure 3 presents the partial plots of linear relationship between each significant regressor and richness after controlling the effects of the other variables. The plots confirm that RT and Sd have the greatest impacts as each accounted for about $82 \%$ of the variance $\left(\mathrm{R}^{2}\right.$ Linear) (Figure $\left.3-b, d\right)$, while $\mathrm{E}$ and $\mathrm{M}$ explained $51 \%$ and $57 \%$, respectively (Figure 3-a,c). The model residuals for regression assumptions of homoscedasticity and normality are presented in Figure 4. Based on the unstandardized coefficients (B) values, the relationship between model 4 and richness can be expressed by the following MLR equation.

$$
\begin{aligned}
\text { Richness }= & 1.832-(4.258 \text { Rock type })+(0.033 \text { Elevation }) \\
& +(0.125 \text { Slope degree })+(0.138 \text { Moisture }) \\
& -(0.300 \text { Organic matter })
\end{aligned}
$$


Table 2. MLR between richness as response and a) the single groups of rock type, soil, or environmental factors as predictors (models 1,2,3) before combining variables from the three groups, $b$ ) their joint effects as predictors (model 4) after combining variables from all three groups $(95 \%$ CI; $N=17)$

\begin{tabular}{|c|c|c|c|c|c|c|c|c|c|}
\hline Models & $\mathbf{R}$ & $\mathbf{R}^{2}$ & Adj. $\mathbf{R}^{2}$ & $\begin{array}{c}\text { F- } \\
\text { ratio }\end{array}$ & $\mathbf{P}$ & Predictors & B & $\mathbf{t}$ & $\mathbf{p}$ \\
\hline \multirow{2}{*}{1} & \multirow{2}{*}{.411} & \multirow{2}{*}{.169} & \multirow{2}{*}{.113} & \multirow{2}{*}{3.044} & \multirow{2}{*}{.101} & Constant & 10.682 & 5.013 & .000 \\
\hline & & & & & & Rock type & -2.591 & -1.745 & .101 \\
\hline \multirow{5}{*}{2} & \multirow{5}{*}{.376} & \multirow{5}{*}{.141} & \multirow{5}{*}{-.145} & \multirow{5}{*}{.494} & \multirow{5}{*}{.741} & Constant & 6.546 & .573 & .578 \\
\hline & & & & & & Soil depth & -.017 & -.524 & .610 \\
\hline & & & & & & Moisture & .129 & 1.071 & .305 \\
\hline & & & & & & $\mathrm{PH}$ & -.196 & -.128 & .900 \\
\hline & & & & & & Organic matter & -.322 & -.790 & .445 \\
\hline \multirow{6}{*}{3} & \multirow{6}{*}{.752} & \multirow{6}{*}{.565} & \multirow{6}{*}{.368} & \multirow{6}{*}{2.860} & \multirow{6}{*}{.068} & Constant & -2.110 & -.169 & .869 \\
\hline & & & & & & Elevation & .057 & 2.570 & .026 \\
\hline & & & & & & Slope degree & .097 & 2.414 & .034 \\
\hline & & & & & & Canopy Cover & -.081 & -1.701 & .117 \\
\hline & & & & & & Ground Cover & .022 & 0.621 & .547 \\
\hline & & & & & & Ground Temperature & .082 & 0.165 & .872 \\
\hline \multirow{6}{*}{4} & \multirow{6}{*}{.956} & \multirow{6}{*}{.914} & \multirow{6}{*}{.875} & \multirow{6}{*}{23.318} & \multirow{6}{*}{.000} & Constant & 1.832 & 1.209 & .252 \\
\hline & & & & & & Rock type & -4.258 & -7.083 & .000 \\
\hline & & & & & & Elevation & .033 & 3.367 & .006 \\
\hline & & & & & & Slope degree & .125 & 7.105 & .000 \\
\hline & & & & & & Moisture & .138 & 3.816 & .003 \\
\hline & & & & & & Organic Matter & -.300 & -2.100 & .060 \\
\hline
\end{tabular}

$\mathrm{R}^{2}$ and adjusted $\mathrm{R}^{2}$ (adj. $\mathrm{R}^{2}$ ) both indicate the proportion of variance in richness explained by the models. The value of adj. $\mathrm{R}^{2}$ is reported to avoid over-estimation of the success of the models. Adj. $\mathrm{R}^{2}$ is more restrictive and takes into consideration the number of predictor variables, and also the number of observations the model is based on.
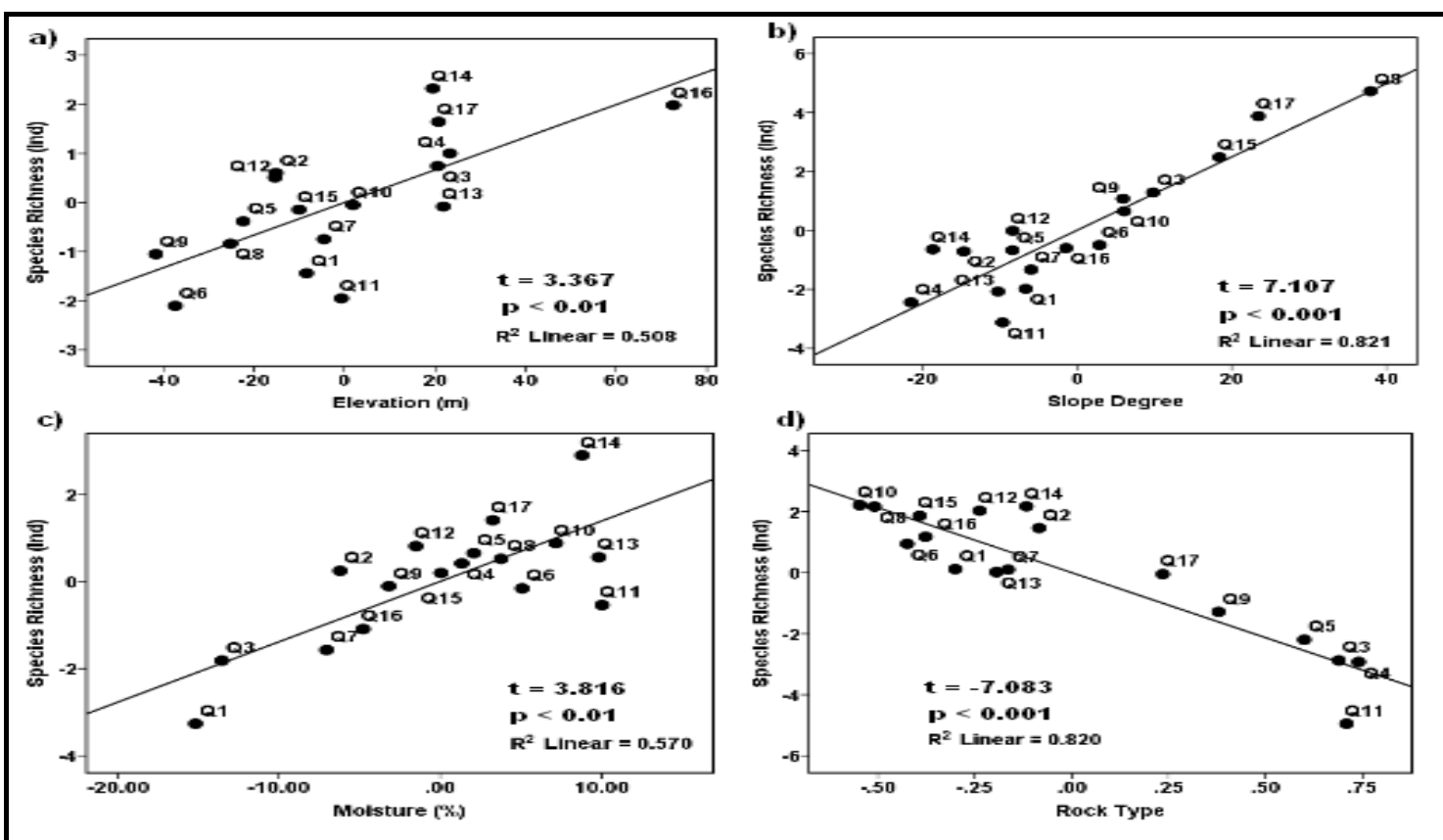

Figure 3. Partial regression plots displaying linear correlations between richness and the significant factors in MLR analysis. $R^{2}$ Linear values indicate the amount of variation explained by each variable while controlling the effects of the other predictors 


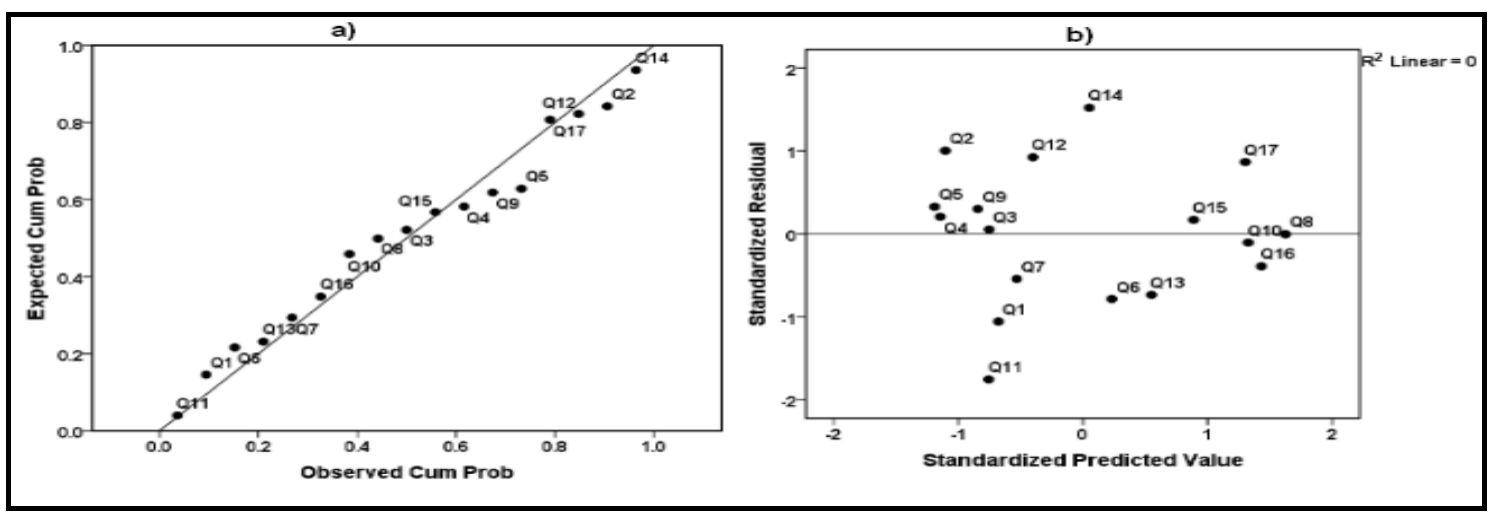

Figure 4. MLR model 4 residuals' plots in predicting richness for regression assumptions of a) Normality: Normal P-P plot of regression standardized residuals vs. standardized predicted values; b) Constant variance: scatterplot of standardized residuals versus standardized predicted values

\section{GzLM Poisson regressions for richness response to the single or combined effects of geological, soil and environmental factors}

The conditional variance of richness was a little higher than its mean, but the difference was not significant. In fact, Negative binomial regression (NBR) model was also applied to see if it gives any improvement over the PR. However, the values of the log-likelihood for the NBR were lower than those of PR, indicating that NB does not improve the models and that the Poisson model form was a better fit. Furthermore, the PR analysis presented no indication of model inadequacy, as the GOF statistics (Deviance, Pearson $X^{2}$ ) were found insignificant $(p>0.05)$ for all four models (Table 3), suggesting that this model form fits the data reasonably well. Nevertheless, the likelihood-ratio chi-square $\left(\mathrm{LR} \mathrm{X}^{2}\right.$ ) of the omnibus tests which compares the fitted model against the intercept-only model (null-model) was insignificant for models 1,2 , and 3. This suggests that there was no improvement over the null-model when examining richness as a function of the single groups of soil, geological, or environmental variables.

In contrast to the first three models, model 4 examined richness as a function of the combination of variables selected from the three groups (RT, E, Sd, M, OM), and the LR $X^{2}$ suggests that the fitted model outperforms the null model (LR $X^{2}=91.423$, $\mathrm{p}<0.001)$. Compared to the models designed with single groups, the values of deviance, Pearson chi-square, and AIC were smaller, while the log-likelihood was higher indicating that model 4 was a better fit. Additionally, the p-values for the coefficients and Wald $\mathrm{X}^{2}$ of the tests of model effects and parameter estimates show that each of the main terms significantly contributed to richness (Table 4), except OM which significance was marginal $(\mathrm{p}=0.071)$. There was a positive trend of richness with $\mathrm{E}, \mathrm{Sd}$, $\mathrm{M}$, and in dolomite dominated areas, but a negative trend with OM. According to the values of $\operatorname{Exp}(\mathrm{B})$, the incidence rate (IR) for dolomite areas was 1.837 times that of limestone areas. The percent change in the IR of richness was an increase of $0.4 \%$ for each meter increase in E, $1.6 \%$ for a degree increase in slope, $2 \%$ for every percent increase in $\mathrm{M}$, but a decrease of about $4 \%$ for every percent increase in OM, while holding the other variables at constant. The plot of deviance residuals against the estimated linear predictors for model 4 is presented in Figure 5. Thus, based on the 
estimated coefficients (B) values, species richness as a function of soil, geological, and environmental variables, can be expressed by the following PR equation.

\section{$\log$ (Richness)}

$$
\begin{aligned}
& =0.011+0.608 \text { Dolomite }+0.004 \text { Elevation }+0.016 \text { Slope degree } \\
& +0.020 \text { Moisture }-0.044 \text { Organic matter }
\end{aligned}
$$

$$
\begin{aligned}
\text { Richness }= & (e)^{0.011} \times(e)^{0.608 \text { Dolomite }} \times(e)^{0.004 \text { Elevation }} \times(e)^{0.016 \text { Slope degree }} \\
& \times(e)^{0.020 \text { Moisture }} \times(e)^{-0.044 \text { Organic matter }}
\end{aligned}
$$

Table 3. Poisson GOF tests between richness as response and the single group of

\begin{tabular}{|c|c|c|c|c|c|}
\hline Model & Predictors & Tests & Value & $\overline{\text { Df }}$ & $\mathbf{P}$ \\
\hline \multirow{5}{*}{1} & \multirow{5}{*}{ Rock type } & Deviance & 17.716 & 15 & 0.278 \\
\hline & & Pearson $\mathrm{X}^{2}$ & 18.986 & 15 & 0.214 \\
\hline & & Log Likelihood & -40.683 & - & - \\
\hline & & AIC & 85.367 & - & - \\
\hline & & LR X $^{2}$ (Omnibus Test) & 2.993 & 1 & 0.084 \\
\hline \multirow{5}{*}{2} & \multirow{5}{*}{$\begin{array}{c}\text { Elevation } \\
\text { Slope degree } \\
\text { Ground cover } \\
\text { Ground } \\
\text { temperature }\end{array}$} & Deviance & 12.251 & 12 & 0.426 \\
\hline & & Pearson $\mathrm{X}^{2}$ & 11.822 & 12 & 0.460 \\
\hline & & Log Likelihood & -37.951 & - & - \\
\hline & & AIC & 85.901 & - & - \\
\hline & & LR X $^{2}$ (Omnibus Test) & 9.394 & 4 & 0.052 \\
\hline \multirow{5}{*}{3} & \multirow{5}{*}{$\begin{array}{c}\text { Soil depth } \\
\text { Moisture } \\
\text { pH } \\
\text { Organic matter }\end{array}$} & Deviance & 18.359 & 12 & 0.105 \\
\hline & & Pearson $\mathrm{X}^{2}$ & 17.953 & 12 & 0.117 \\
\hline & & Log Likelihood & -41.005 & - & - \\
\hline & & AIC & 92.010 & - & - \\
\hline & & LR X ${ }^{2}$ (Omnibus Test) & 2.102 & 4 & 0.717 \\
\hline \multirow{5}{*}{4} & \multirow{5}{*}{$\begin{array}{c}\text { Rock type } \\
\text { Elevation } \\
\text { Slope degree } \\
\text { Moisture } \\
\text { Organic matter }\end{array}$} & Deviance & 2.366 & 11 & 0.997 \\
\hline & & Pearson $X^{2}$ & 2.303 & 11 & 0.997 \\
\hline & & Log Likelihood & -33.009 & - & - \\
\hline & & AIC & 78.017 & - & - \\
\hline & & LR X $^{2}$ (Omnibus Test) & 91.423 & 5 & 0.000 \\
\hline
\end{tabular}
geological, environmental or soil factors as predictors (model 1,2, 3) before combining variables from all groups, and their joint effects as predictors (model 4) after combining variables from all groups (95\% CI; $N=17$ )

AIC: Akaike's Information Criterion; LR $\mathrm{X}^{2}$ : Likelihood ratio chi-square; Df: degree of freedom; P: Significance p-values

Table 4. Poisson regression model 4 tests of model effects and parameter estimates in predicting richness

\begin{tabular}{|c|c|c|c|c|c|}
\hline Model & Parameters & Coefficients $(\mathbf{B})$ & Wald X $^{\mathbf{2}}(\mathbf{D f}=\mathbf{1})$ & Sig. $\mathbf{P}$ & $\operatorname{Exp}(\mathbf{B})$ \\
\hline \multirow{4}{*}{} & Intercept & 0.011 & 0.002 & 0.964 & 1.011 \\
\cline { 2 - 6 } & Rock type $=1$ & 0.608 & 36.017 & 0.000 & 1.837 \\
\cline { 2 - 6 } & Rock type $=2$ & 0 & - & - & 1 \\
\cline { 2 - 6 } & Elevation & 0.004 & 9.410 & 0.002 & 1.004 \\
\cline { 2 - 6 } & Slope degree & 0.016 & 41.005 & 0.000 & 1.016 \\
\cline { 2 - 6 } & Moisture & 0.020 & 10.534 & 0.001 & 1.020 \\
\cline { 2 - 6 } & Organic matter & -0.044 & 3.268 & 0.071 & 0.957 \\
\hline
\end{tabular}




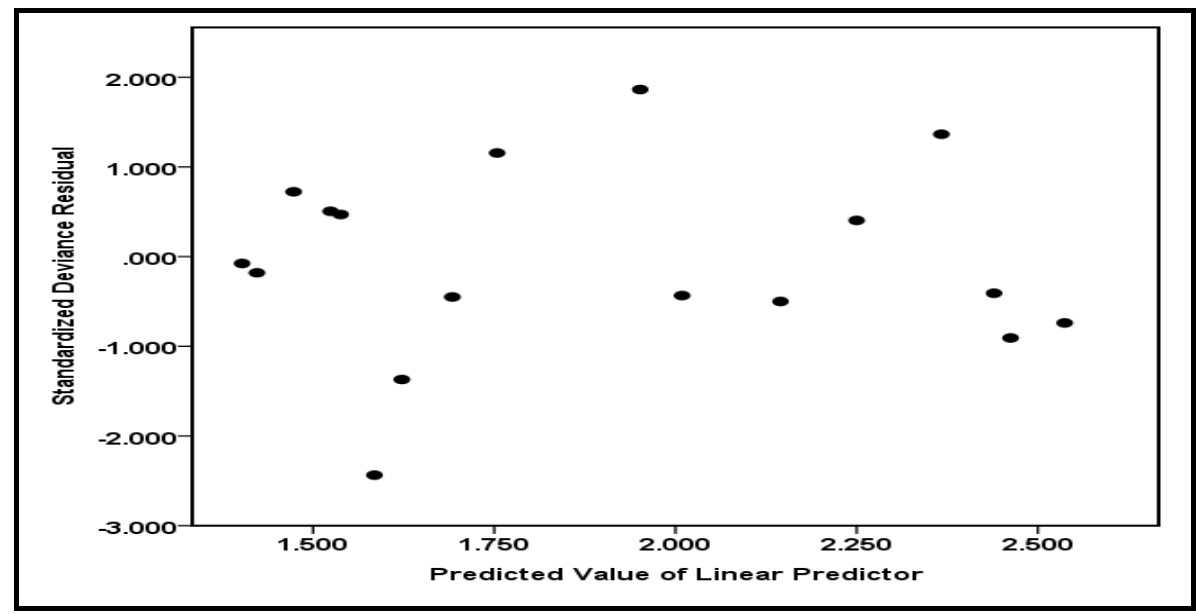

Figure 5. Poisson regression model 4 plot of standardized deviance residuals versus the predicted values of linear predictors

\section{Discussion}

Analysis of variables related to environmental and geological factors revealed some of their interactions with Longhushan soils upon which plant species depend. With correlation and ANOVA procedures we assumed there was insufficient evidence to establish associations between richness and the predictors. ANCOVA established a relationship between richness and ST confirming the findings of Sala et al., (1997) and that ST, RT, M, and GC have some interactions feedbacks on richness. The association between ST and plant richness may be explained by the fact that soil texture affects soil behavior particularly its retention capacity for nutrients and water (Brown, 2003), which availability have significant feedback on plant composition, distribution, and performance. Water availability is also reported as one of the most important environmental parameters controlling plant richness (Lavers and Field, 2006), and it is said to be even more profound in environments where soil moisture is a major limiting resource like karst areas.

Furthermore, GLM and GzLM methods both failed to prove that the soils, geological, or environmental variables examined separately, have significant effects on richness. In contrast, strong associations were observed when variables from the three groups were combined to test their joint effects. In both methods, the combination of RT, E, Sd, M, and OM was found as the best fit for richness, which increased with $\mathrm{M}, \mathrm{Sd}, \mathrm{E}$, and in dolomite areas, but decreased with OM content. The results thereby, revealed species' associations with rock type, water and nutrient availability combined with topographic factors, supporting the conclusions of other researches (Pausas and Carreras, 1995; Leathwick et al., 1998; Clark et al., 1998; Hawkins et al., 2003; Cannon and Leighton, 2004; Valencia et al., 2004; Engelbrecht, 2007; Fayolle et al., 2012). They contrasted however, with studies which found a decreasing trend in species richness with altitude (Pausas, 1994; ReyBenayas, 1995; Odland and Birks, 1999). Nonetheless, the length of elevation gradient of our surveyed plots varied from 109 to $243 \mathrm{~m}$, further studies that cover higher elevations perhaps could help confirm the exact trend. Moreover, in both methods, OM (nutrients store for plants) contributed less to the fit of the regression equations. Yet, there was some trend (its effect was found marginally significant) 
and its presence in the models was essential for the predictability of richness, suggesting that OM content in soil should be considered when examining the relationships between environmental factors and plants in karst habitats.

A particularity of these findings is that rock type was found among the most significant environmental factors that explained richness, and this agreed with other studies (Pausas and Carreras, 1995; Fayolle et al., 2012). In this case there was significant difference in richness between dolomite and calcite areas, suggesting that carbonate rock type may be a key factor in karst habitats as it was found with a strong effect, and its inclusion in the models was determinant in predicting richness. There was positive trend of richness in high dolomite percentage areas but the inverse trend in calcite dominated areas. We may postulate for instance that since the predictable variation in species richness is important in determining areas of conservation, this geological factor is an indicator of high species richness areas in the Longhushan Karst Mountains, which could be used for assigning priority sites for conservation or restoration.

Another particularity is that $\mathrm{OM}$ content was negatively associated with plant richness. The negative trend could be related to a slow decomposition of OM resulting in its accumulation and the tie up of nutrients that are held in it. As reported by Foth, (2006), high organic matter contents in soils are the result of slow decomposition rates rather than high rates of organic matter addition. The ability of species to perform at different resource availability levels was discussed by Grime, $(1973,1977)$ who reported that few species can tolerate the stress characteristic of low-resource habitats. As productivity increases, more resources become available, thereby relaxing the abiotic stress and allowing the establishment and growth of more species.

The slow decomposition of OM could be due to several factors, as the rate of decomposition is mainly dependent on the abundance of soil microbes (e.g. bacteria, fungi), the substrate quality (nutrient content: $\mathrm{C} / \mathrm{N}$ ratios, $\mathrm{OM}$ composition, etc), and soil environmental conditions ( $\mathrm{pH}$, moisture, texture, temperature, etc). The analysis showed that over $88 \%$ of the sampled plots have insufficient available moisture, while soil biological activity requires sufficient air and moisture. In fact, it is said that optimal microbial activity occurs at near "field capacity", which is equivalent to $60 \%$ waterfilled pore space (Linn and Doran, 1984). In addition to the insufficient moisture content, the results also showed that about $75 \%$ of the sampled plots was dominated by fine and medium textured soil indicating high clay content, while clay particles are believed to protect some of the more easily decomposable organic compounds from rapid microbial breakdown through encrustation and entrapment (Paul and vanVeen, 1978; Anderson, 1979; Tisdall and Oades, 1982). Therefore, although the two factors (moisture and texture) may not be totally enough to explain the negative association between plant species and OM content, but the lack of adequate soil moisture combined with the dominance of finer textured soil may have contributed to limited microbial metabolisms, resulting in the accumulation of organic matter and the tied up of nutrients needed by the plant species to perform. This conclusion supports those of Woods and Raison, (1983) who suggested that moisture was a major factor in controlling OM decomposition, and Killham et al., (1993) reported that substrate utilization by microbes in soil is strongly affected by its location, both in terms of pore size and the matric water potential under which turnover takes place. Nevertheless, it should be noted that further studies in the reserve might help to further explain the different factors that 
affect OM decomposition in karst areas and their impact on plants. For instance, the microbial biomass, the substrate quality (OM composition, $\mathrm{C}: \mathrm{N}$ ratios), and the anthropogenic disturbance on different ecological processes could represent interesting subjects for future studies to better understand the complexity of processes OM undergoes in order to establish suitable management strategies.

\section{Distribution of dominant species along significant environmental gradients}

Key species or function groups are known to play an important role in maintaining the whole karst ecosystem (Wang et al., 2002; Ackerly, 2004). Figure 6 analyzes how the significant factors influenced the dominant species distribution in the reserve. The dominant species responded differently to the significant factors and a number of those species were found typically well adapted to the special karst environment. Among them Ficus sp. was only adapted in high dolomite percentage areas, while the remaining species were all apt to survive in both habitats (dolomite or calcite) (Figure 6a), confirming the fact that some limestone species conform well to a calcium rich environment (Mao and Zhang, 1987; Xu, 1993). Most dominant species were also suitable for habitats with sufficient and insufficient moisture conditions, except Ficus sp. recorded only in low moisture habitats (Figure $6 b)$, suggesting that this species was adapted to extreme drought situation. Sterculia nobilis, Teonongia tonkinensis, and Albizia chinensis were susceptible to live at both slight and steep slopes (Figure 6c), and also at all elevations (Figure 6d).

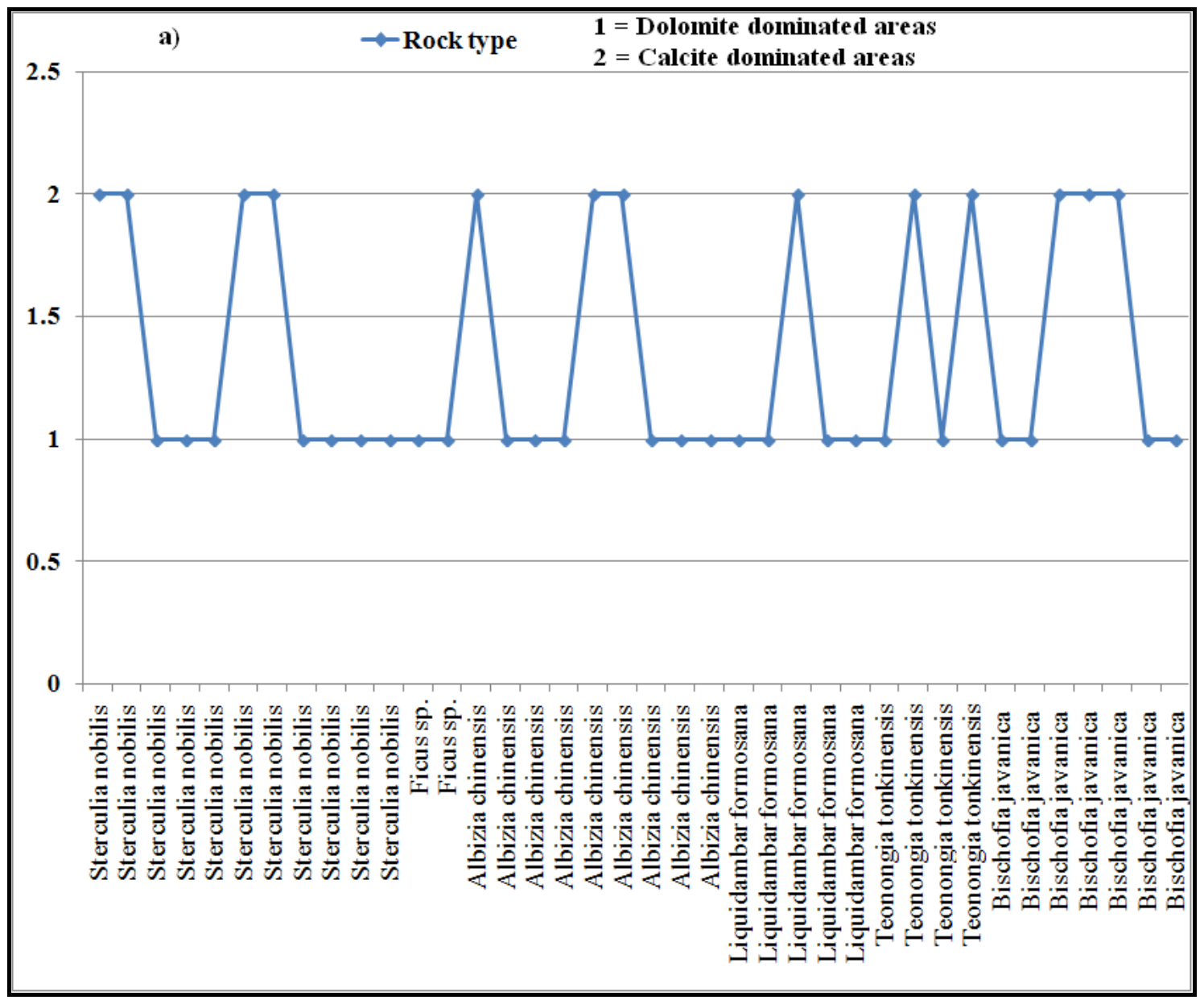




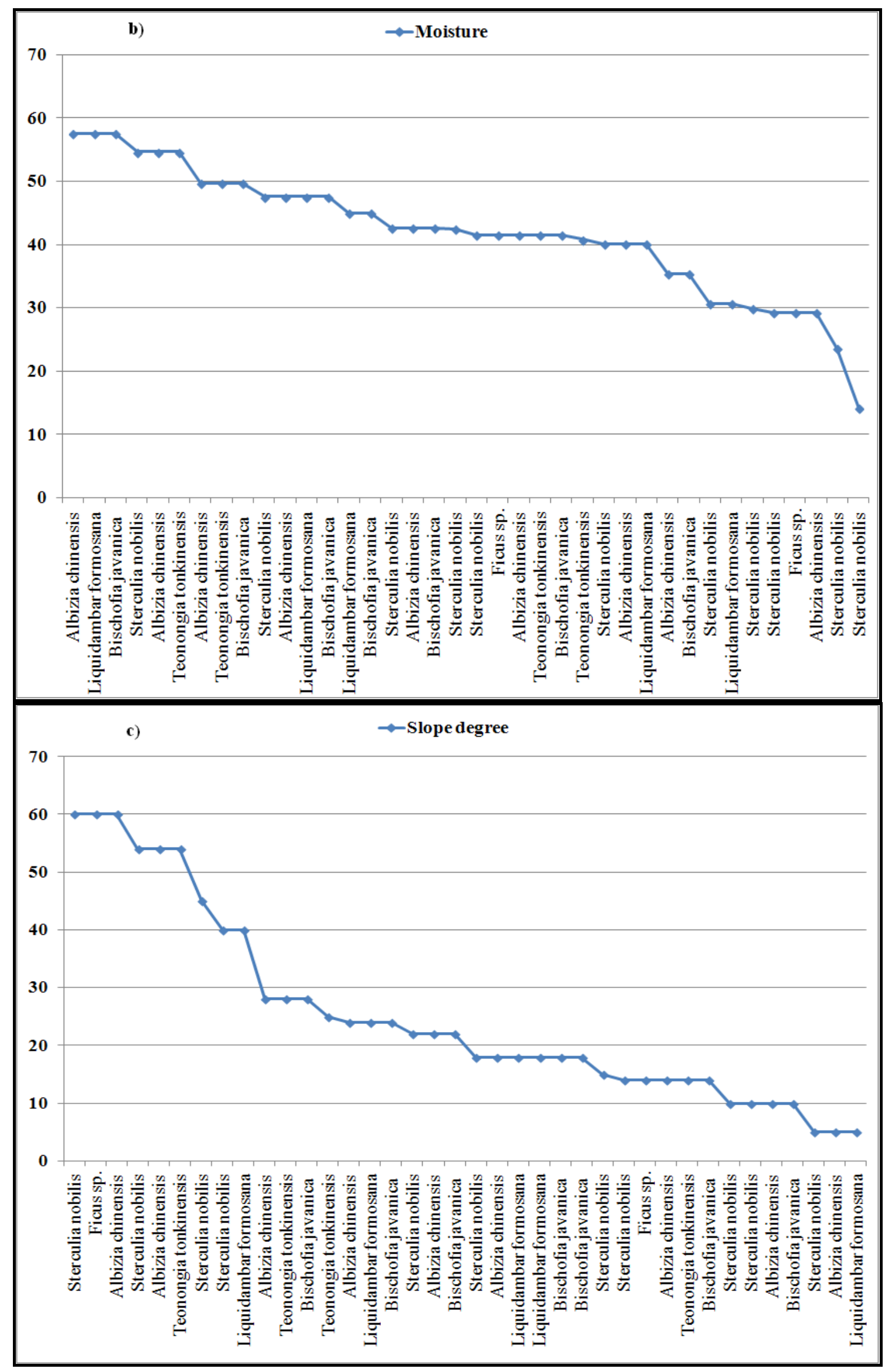




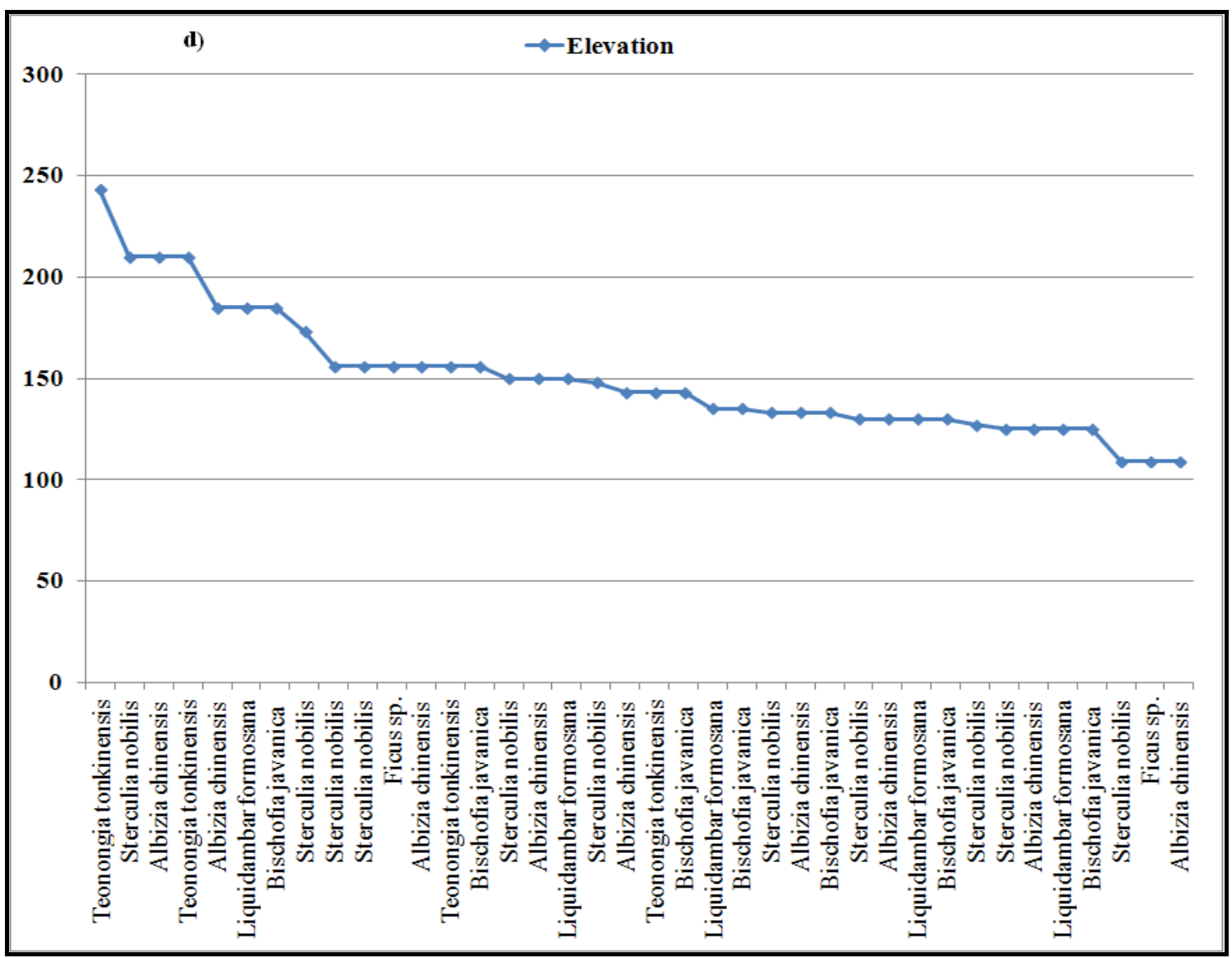

Figure 6. Dominant species distribution along a) rock type, b) moisture, c) slope degree, and d) elevation, as significant environmental factors in LNR

Ficus sp., Liquidambar formosana, and Bischofia javanica were suitable to live at low and middle elevations, while Bischofia javanica grew only at slight slopes. Each of these species performed well in their habitats suggesting they could be appropriate for the restoration of degraded parts of the mountains with similar conditions. For instance, the fragmented areas by tourist roads network, the denuded ground by primate damage, or the abandoned agricultural lands which are all exposed at risk of erosion. Based on the dominant species response to the significant environmental factors, Sterculia nobilis and Albizia chinensis appears to be the most appropriate species for restoration and forest amelioration measures, since they were suitable to all karst environmental habitats conditions.

Moreover, although found with the lowest IVs, several other species including Allophylus caudatus, Alphonsea mollis, Bridelia balansae, Canthium dicoccum, Eurya groffii, Hartia sinensis, Litsea variabilis, Murraya kwangsiensis, Cinnamomum saxatile, Diospyros eriantha, Ficus glaberrima, and Hainania trichosperma were recorded only at high elevations. These species might be endangered as most of them were found just once in the reserve or in one quadrat, thus need special protection for the conservation of biological diversity of the area. In fact, among them Canthium dicoccum is included in the UICN Red List for endangered species and Hainania trichosperma is an endemic species. 


\section{Conclusion}

In LNR, variations in plant richness were dependent on complex relationships between soil, environmental, and geological factors of karst habitats. Within this complexity of relationships it appeared that the geological factor played an important role in the spatial patterns of plant species in the area. Patterns in richness were related to rock type, soil moisture, texture, and nutrient status combined with topographic factors. The strong association between tree species richness and rock type, on which soils develop with different properties and consequently different water and nutrient availability, suggests that soil resources availability is important for these patterns.

The results clearly demonstrated that the evidence of significant variation in richness was provided after combining variables from soil, geological, and environmental factors, suggesting their interactions influence on plants. Evidence supports these interactions and no single context explained the different associations between richness and any group of factors. The findings have implications for the understanding of these interactions and suggest that not only plant species can be affected by it, but also rock type may be an important parameter influencing the overall relationships between plant species and other environmental habitat factors in karst areas. Therefore, effective and efficient management of karst forest ecosystems requires an elaborate data set and understanding of all the components and physical features, as well as the complex links and interactions between them and plant communities, if species and their habitats are to be managed in a way that can sustain their diversity. This information can provide a reference for assigning priority sites for biodiversity conservation, prevention of rock desertification, and development of sustainable management, conservation, and restoration strategies of karst ecosystems.

Acknowledgements. This work was supported by the grants from the Natural Scientific Foundation of China (No. 40972218) and the Fundamental Research Founds for National University, China University of Geosciences (Wuhan) (No. G1323521125, No. G1323521225, G1323521325).

\section{REFERENCES}

[1] Acharya, B.K., Chettri, B., Vijayan L. (2011): Distribution pattern of trees along an elevation gradient of Eastern Himalaya India. - Acta Oecol 37: 329-336.

[2] Ackerly, Y. (2004): Functional strategies of chaparral shrubs in relation to seasonal water deficit and disturbance. - Ecol. Monogr 74: 25-44.

[3] Anderson, D.W. (1979): Processes of humus formation and transformation in the soils of the Canadian Great Plains. - Journal of Soil Science 30: 77-84.

[4] Austin, M.P., Pausas, J.G., Nicholls, A.O. (1996): Patterns of species richness in relation to environment in southeastern New South Wales, Australia. - Australian Journal of Ecology 21: 154-164.

[5] Brown, R.B. (2003): Soil Texture Fact Sheet SL-29. - University of Florida, Institute of Food and Agricultural Sciences.

[6] Cannon, C.H., Leighton, M. (2004): Tree species distributions across five habitats in a Bornean rain forest. - Journal of Vegetation Science 15: 257-266.

[7] Cao, J., Yuan, D.X., Pan, G. (2003): Some soil features in karst ecosystem. - Advance in Earth Sciences 18(1): 37-44. 
[8] Chawla, A., Rajkumar, S., Singh, K.N., Lal, B., Singh, R.D., Thukral, A.K. (2008): Plant species diversity along an altitudinal gradient of Bhabha Valley in western Himalaya. Journal of Mountain Science 5: 157-177.

[9] Clark, D.B., Clark, D.A., Read, J.M. (1998): Edaphic variation and the mesoscale distribution of tree species in a neotropical rain forest. - Journal of Ecology 86: 101-112.

[10] Cottle, R. (2004): Linking Geology and Biodiversity. - External Relations Team, English Nature Report No 562 Peterborough, pp. 11, 12, 84. http://www.cbd.int/doc/pa/tools/Linking\%20Geology\%20and\%20Biodiversity\%20(part\% 201).pdf

[11] Eberhard, R. (1994): Inventory and management of the Junee River Karst system, Tasmania. - Forestry Tasmania, Hobart.

[12] Engelbrecht, B.M.J., Comita, L.S., Condit, R., Kursar, T.A., Tyree, M.T., Turner, B.L., Hubbell, S.P. (2007): Drought sensitivity shapes species distribution patterns in tropical forests. - Nature 447: 80-83.

[13] Fayolle, A., Engelbrecht, B., Freycon, V., Mortier, F., Swaine, M., et al. (2012): Geological substrates shape tree species and trait distributions in African moist forests. PLOS ONE 7(8):e42381. Doi: 10.1371/journal.pone.0042381.

[14] Foth, H.D. (2006): Fundamentals of soil science. - John Wiley and Sons, 8th ed., New York.

[15] Friedman, G.M. (1959): Identification of carbonate minerals by staining methods. Journal of Sedimentary Petrology 29: 87-97.

[16] Gong, G.Q., Cheng, J.M., Mi, X.C., Chen, S.W., Fang, T. (2007): Habitat association of wood species in the Gutianshan subtropical broad- leaved evergreen forest. - Sci Soil and Water Conservation 5(3): 79-83.

[17] Grime, J.P. (1973): Competitive exclusion in herbaceous vegetation. - Nature 242: 344347.

[18] Grime, J.P. (1977): Evidence for the existence of three primary strategies in plants and its relevance to ecological and evolutionary theory. - American Naturalist 111: 1169-1194.

[19] Grytnes, J.A. (2003b): Ecological interpretations of the mid-domain effect. - Ecol Lett 6: 883-888.

[20] Harris, R.W., Coppock, R.H. (1991): Saving water in landscape irrigation. - Oakland, CA University of California, Division of Agriculture and Natural Resources, Publication University of California (System) 2976.

[21] Hartz, T.K. (2007): Soil Testing for Nutrient Availability, Procedures and Interpretation for California Vegetable Crop Production. - University of California, Vegetable Research and Information Center, 1-7.

[22] Hawkins, B.A., et al. (2003): Energy, water, and broad-scale geographic patterns of species richness. - Ecology 84: 3105-3117.

[23] Hu, Z.L., Pan, G.X., Li, L.Q., Du, Y.X., Wang, X.Z. (2009): Changes in pools and heterogeneity of soil organic carbon, nitrogen and phosphorus under different vegetation types in Karst mountainous area of central Guizhou Province, China. - Acta Ecologica Sinica 29: 1-9.

[24] Killham, K., Amato, M., Ladd, J.N. (1993): Effect of substrate location in soil and soil pore-water regime on carbon turnover. - Soil Biology and Biochemistry 25: 57-62.

[25] Körner, C. (2002): Mountain biodiversity, its causes and function: an overview. - In: Körner, C., Spehn, E.M. (ed) Mountain Biodiversity: A Global Assessment, Parthenon Publishing Group, NY, pp. 3-18.

[26] Laurance, W.F. (2007): Forest destruction in tropical Asia. - Current Science 93: 15441550.

[27] Lavers, C., Field, R. (2006): A resource-based conceptual model of plant diversity that reassesses causality in the productivity-diversity relationship. - Global Ecology and Biogeography 15: 213-224. 
[28] Leathwick, J.R., Burns, B.R., Clarkson, B.D. (1998): Environmental correlates of tree alpha-diversity in New Zealand primary forests. - Ecography 21: 235-246.

[29] Linn, D.M., Doran, J.W. (1984): Aerobic and anaerobic microbial populations in no-till and plowed soils. - Soil Science Society of America Journal 48: 794-799.

[30] Liu, C.Q. (2009): Biogeochemical processes and cycling of nutrients in the Earth's surface: cycling of nutrients in soil-plant systems of Karstic Environments, southwest China. - Science Press, Beijing, China.

[31] Liu, F., Wang, S.J., Luo, H.B., Liu, Y.S., He, T.B., Long, J. (2006): Vegetation succession with Karst desertification and its impact on water chemistry of runoff. - Acta Pedol Sinica 43: 26-32.

[32] Liu, S,L., Ma, K.M., Fu, B.J., Kang, Y.X., Zhang, J.Y., Zhang, Y.X. (2003): The relationship between landform, soil characteristics and plant community structure in the Donglingshan Mountain Region, Beijing. - Acta Phytoecologica Sinica 27: 496-502.

[33] Lomolino, M.V. (2001): Elevation gradients of species-density: historical and prospective views. - Global Ecol Biogeogr 10: 3-13.

[34] Mao, Z.Z., Zhang, B. (1987): The geological characteristics of the Maolan karst forest. In: Zhou Zhengxian (ed.) Scientific Survery of the Maolan Karst Forest, The People's Publishing House of Guizhou, pp. 24-41.

[35] Margules, C.R., Nicholls, A.O., Austin, M.P. (1987): Diversity of Eucalyptus species predicted by multi-variable environmental gradient. - Oecologia 71: 229-332.

[36] McDonald, D.J., Cowling, R.M., Boucher, C. (1996): Vegetation- environment relationships on a species-rich coastal mountain range in the fynbos biome. - Plant Ecology 123: 165-182.

[37] Moritz, C. (2002): Strategies to protect biological diversity and the evolutionary processes that sustain it. - Syst Biol 51: 238-254.

[38] Nielson, D.W., Sommers, L.E. (1982): Particle size analysis. - In: American Society of Agronomy-Soil Science (2nd ed) Methods of soil analysis part 2, Chemical and microbiolgical properties, Society of America, Madison, pp. 539-577.

[39] Odland, A., Birks, H.J.B. (1999): The altitudinal gradient of vascular plant species richness in Aurland, western Norway. - Ecography 22: 548-566.

[40] Paul, E.A., vanVeen, J.A. (1978): The use of tracers to determine the dynamic nature of organic matter. - International Congress of Soil Science, Transactions of the 11th Symposia Papers Edmonton 3: 61-102.

[41] Pausas, J.G. (1994): Species richness patterns in the understory of Pyrenean Pinus sylvestris forest. - J Veg Sci 5: 517-524.

[42] Pausas, J.G., Carreras, J. (1995): The effect of bedrock type, temperature and moisture on species richness of Pyrenean Scots pine (Pinus sylvestris L.) forests. - Vegetatio 116: 8592.

[43] Peet, R.K. (1974): The measurement of species diversity. - Annual Review of Ecology and Systematics 5: 285-307.

[44] Phillips, O.L., Vargas, P.N., Monteagudo, A.L., Cruz, A.P., Chuspezans, M.E., et al. (2003): Habitat association among Amazonian tree species: a landscape-scale approach. Journal of Ecology 91: 757-775. Doi: 10.1046/j.1365-2745.2003.00815.x.

[45] Rahbek, C. (2005): The role of spatial scale and the perception of large scale speciesrichness patterns. Ecol Lett 8: 224-239.

[46] Reiners, W. (2002): Geological control of plant species distribution in Wyoming, Abstracts from: Geology, Biogeochemistry, and Ecology: A New Synthesis for Arid Landscape Processes. - Geological Society of America, Annual Conference, Denver.

[47] ReyBenayas, J.M. (1995): Patterns of diversity in the strata of boreal forest in British Columbia. - J Veg Sci, 6: 95-98.

[48] Rosenzweig, M.L. (1995): Species diversity in space and time. - Cambridge University Press, NY. 
[49] Sagar, R., Raghubanshi, A.S., Singh, J.S. (2003): Tree species composition, dispersion, and diversity along a disturbance gradient in a dry tropical forest region of India. - Forest Ecology and Management 186: 61-71.

[50] Sala, O.E., Lauenroth, W.K., Golluscio, R.A. (1997): Plant functional types in temperate semi-arid regions. - In: Smith, T.M., Shugart, H.H., Woodward, F.I. (eds) Plant functional types, their relevance to ecosystem properties and global change, Cambridge University Press, Cambridge, pp. 217-233.

[51] Sharma, C.M., Suyal. S., Gairola, S., Ghildiyal, S.K. (2009): Species richness and diversity along an altitudinal gradient in moist temperate forest of Garhwal Himalaya. - J Am Sci 5(5): 119-128.

[52] Shen, Z.H., Zhang, X.H., Jin, Y.X. (2000): Gradient analysis of the influence of mountain topography on vegetation pattern. - Acta Phytoecologica Sinica 24(4): 430-435.

[53] Sodhi, N.S., Koh, L.P., Brook, B.W., Ng. P.K.L. (2004): Southeast Asian biodiversity: an impending disaster. - Trends in Ecology and Evolution 19: 654-659.

[54] Sodhi, N.S., Posa, M.R.C., Lee, T.M., Bickford, D., Koh, L.P., Brook, B.W. (2010): The state and conservation of Southeast Asian biodiversity. - Biodiversity and Conservation 19: 317-328.

[55] Song, T.Q., Peng, W.X., Zeng, F.P., Wang, K.L., Ouyang, Z.W. (2008): Vegetation succession rule and regeneration strategies in disturbed karst area, northwest Guangxi. - J Mount Res 26: 597-604. (In Chinese)

[56] terSteege, H., Pitman, N.C.A., Phillips, O.L., Chave, J., Sabatier, D., et al. (2006): Continental-scale patterns of canopy tree composition and function across Amazonia. Nature 443: 444-447. Doi: 10.1038/nature05134.

[57] Tisdall, J.M., Oades, J.M. (1982): Organic matter and water-stable aggregates in soils. Journal of Soil Science 33: 141-163.

[58] Tuomisto, H., Poulsen, A.D., Ruokolainen, K., Moran, R.C., Quintana, C., et al. (2003): Linking floristic patterns with soil heterogeneity and satellite imagery in Ecuadorian Amazonia. - Ecol Appl 13: 352-371. Doi: 10.1890/00129658(2001)082[2101:dadots]2.0.co;2.

[59] Valencia, R., Foster, R.B., Villa, G., Condit, R., Svenning, J.C., Hernandez, C., et al. (2004): Tree species distributions and local habitat variation in the Amazon: large forest plot in eastern Ecuador. - Journal of Ecology 92: 214-229.

[60] Wang, G.H., Zhou, G.S., Yang, L.M., Li, Z.Q. (2002): Distribution, species diversity and life-form spectra of plant communities along an altitudinal gradient in the northern slopes of Qilianshan Mountains, Gansu, China. - Plant Ecology 165: 169-181.

[61] Warne, S.StJ. (1962): A quick field or laboratory staining scheme for the differentiation of the major carbonate minerals. - Journal of Sedimentary Petrology 32: 29-38.

[62] Webb, C.O., Slik, J.W.F., Triono, T. (2010): Biodiversity inventory and informatics in Southeast Asia. - Biodiversity and Conservation 19: 955-972.

[63] Woods, P., Raison, R.J. (1983): Decomposition of litter in sub-alpine forests of Eucalyptus delegatensis, E. Pauciflore and E. divers. - Australian Journal of Ecology 8: 287-299.

[64] Wu, H.Y., Peng, W.X., Song, T.Q., Zeng, F.P., Li, X.H., Song, X.J., Ouyang, Z.W. (2008): Changes of soil nutrients in process of natural vegetation restoration in karst disturbed area in northwest Guangxi. - Journal of Soil and Water Conservation 22: 143147. (In Chinese)

[65] Wu, Y., Liu, Q., Qiao, Y.K., Pan, K.W., Zhao, C.M., Chen, Q.H. (2001): Species diversity changes in subalpine coniferous forests of different restoration stages and their effects on soil properties. - Acta Phytoecologica Sinica 25: 648-655.

[66] Xu, Z.R. (1993): Studies of the limestone forest in China. - Guihaia supplement IV, 5-54. 
[67] Ye, M.S., Guan, W.B., Tan, H., Ma, K.M., Liu, G.H., Wang, X.L. (2004): The $\alpha$ diversity of shrubs community in the arid valley of the Minjiang River. - Acta Ecologica Sinica 24: 1123-1130.

[68] Yuan, D.X. (1988): On the Karst environmental system. - In Proceedings of the IAH 21st Congress: Karst Hydrology and Karst Environment Protection, Guilin, China, 1: 30-46.

[69] Yuan, D.X. (1993): Environmental change and human impact on karst in south China. In: Williams, P. (ed) Karst terrains: environmental change and human impact, Catena, Supplement 25 p. 104.

[70] Yuan, D.X. (2001): On the karst ecosystem. - Acta Geologica Sinica 75(3): 336-338.

[71] Yue, Y.M., Wang, K.L., Zhang, W., Chen, H.S., Wang, M. (2008): Relationships between soil and environment in peak-cluster depression areas of karst region based on canonical correspondence analysis. - Environmental Science 29: 1400-1405.

[72] Zhang, Z.H., Hu, G., Zhu, J.D., Ni, J. (2010): Spatial patterns and interspecific associations of dominant tree species in two old-growth karst forests, SW China. Ecological Research 25: 1151-1160. 